\title{
Dopaminergic control of LH secretion by the A15 nucleus in anoestrous ewes
}

\author{
J-C. Thiéry, V. Gayrard*, S. Le Corre ${ }^{\dagger}$, C. Viguié, G. B. Martin*, \\ P. Chemineau and B. Malpaux
}

Neuroendocrinologie Sexuelle, PRMD INRA, 37380 Nouzilly, France

\begin{abstract}
Annual variations in the secretion of $\mathrm{LH}$ are responsible for seasonal changes in ovulatory activity in ewes. This hormonal pattern reflects an increase in the intensity of the negative feedback exerted by oestradiol under long days. Neuropharmacological studies have shown that this inhibition of LH secretion involves activation of catecholaminergic systems from preoptic and mediobasal hypothalamus $(\mathrm{MBH})$ by oestradiol during anoestrus, and that 5-hydroxytryptamine inputs may also play a role. Within the $\mathrm{MBH}$, the most important structures appear to be the retrochiasmatic region of the hypothalamus, which contains the A15 dopaminergic nucleus, and the median eminence, which contains the axon terminals of the GnRH cells controlling the pulsatile release of LH. In ovariectomized ewes in which oestradiol tonically inhibits $\mathrm{LH}$ secretion during the anoestrous season, $\mathrm{LH}$ pulse frequency is increased when the cells of the A15 nucleus are destroyed. The median eminence and other mediobasal structures contain more catecholamines and their metabolites under long days than under short days. Microdialysis of the AI5 nucleus in vivo during long days revealed increased catecholaminergic activity under oestradiol treatment due to stimulation of tyrosine hydroxylase, the rate-limiting enzyme in the pathway of catecholaminergic synthesis. Tyrosine hydroxylase activity within the median eminence is increased under the various photoperiodic regimens that inhibit LH secretion. Neurochemical changes in the A15 nucleus and median eminence, in response to photoperiodic or oestradiol treatments, suggest a functional relationship which acts at the level of the GnRH axon terminals.
\end{abstract}

\section{Introduction}

Male and female sheep from temperate latitudes show seasonal variations in reproductive activity. The quantity and quality of sperm production by males decrease during spring. In contrast to males, the seasonal regulation of reproduction in ewes appears to be mainly an all-or-nothing phenomenon. During spring and summer, there is a complete cessation of ovulation and oestrous behaviour in ewes. Changes in daylength during the year are responsible for this alteration in reproductive activity. Under constant artificial daylength of 8 or $16 \mathrm{~h}$ of light per day, the animals exhibit a neuroendocrine state similar to that of the breeding or anoestrous season, respectively (Karsch et al., 1986). Photic information is conveyed to the brain through several relays and results in a nocturnal secretion of melatonin. Thus, the duration of noctumal melatonin secretion, short during long days and long during short days, informs the animal

Present addresses: "Ecole Nationale Vétérinaire 12, Chemin des Capelles, 31070 Toulouse cedex, France, 'University of Oxford, Department of Clinical Pharmacology, Radcliffe Infirmary. Woodstock Road Oxford OX2 6HE. UK; and Faculty of Agriculture. University of Western Australia, Nedlands, WA 0009 . Australia. 


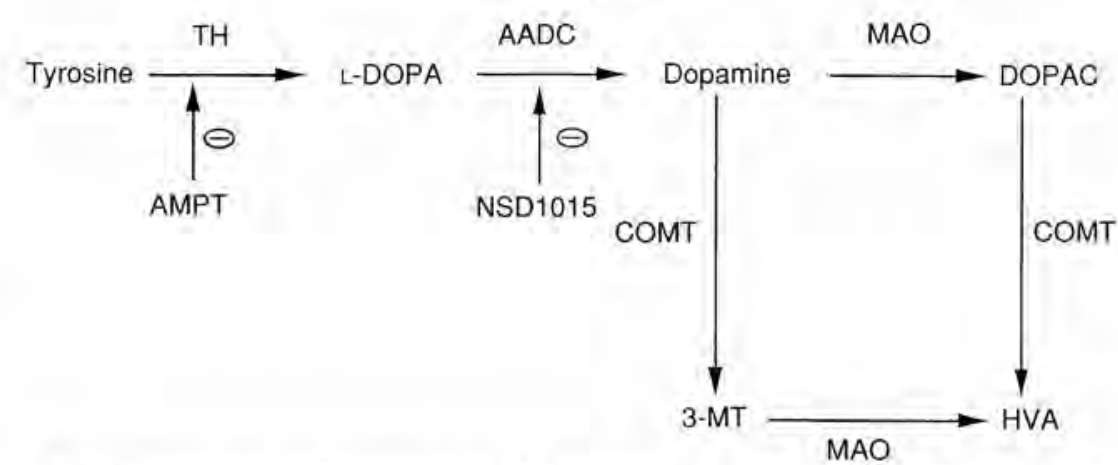

Fig. 1. Biosynthesis and degradation of dopamine. The enzymes tyrosine hydroxylase (TH) and I-aromatic amino acid decarboxylase (AADC) act successively on tyrosine and L-3-4-dihydroxyphenylalanine ( $\mathrm{L}-\mathrm{DOPA})$ to produce dopamine. This molecule is then transformed into 3,4-dihydroxyphenylacetic acid (DOPAC) and homovanilic acid (HVA) by two pathways, involving monoamine oxidase (MAO) and catechol-O-methyltransferase (COMT). AMPT (alpha methyl tyrosine) and NSD 1015 are specific inhibitors of $T H$ and $A A D C$, respectively, allowing manipulation of the enzymatic activities.

of the time of year. Melatonin in turn acts on brain structures to trigger the necessary changes resulting in the modification of gonadotrophin secretion (Malpaux et al, 1989). There is a large gap in our knowledge of the mechanisms involved between the effective site(s) of action of melatonin, still the subject of controversy (Malpaux et al, 1993, 1994), up to the GnRH-producing cells that govern the pulsatile LH release by the pituitary gland. In this review some of the neuronal systems of the hypothalamus involved in the seasonal control of the activity of GnRH neurones will be discussed. The differences in the variations of reproductive activity between males and females probably parallel different mechanisms that can control the reproductive activity in both sexes. However, less is known about the brain regulation of gonadotrophin secretion in male sheep and regulation in females only will be discussed. The data showing the involvement of one given family of neurotransmitters, the monoamines, will be described with particular emphasis on catecholamines. Among catecholamines, the role of dopamine in the inhibition of GnRH secretion in female sheep in particular will be examined, as well as one of the intrahypothalamic nuclei producing it, the A15 dopaminergic nucleus. The metabolic pathways for biosynthesis and degradation of dopamine are shown in Fig. 1.

Much work has been done in ewes to study the involvement of monoaminergic neurotransmitters in the regulation of gonadotrophin secretion by the brain (see Thiéry and Martin, 1991 for review) but this has mostly concerned preovulatory mechanisms. These studies demonstrated a stimulatory role of monoamine on LH secretion, which was later confirmed when the amplitude of LH pulses was observed (Meyer and Goodman, 1986). In contrast, inhibitory effects of monoamine have also been demonstrated for ewes, as Deaver et al. (1987) found that peripheral treatment with a drug that blocks dopamine receptors (domperidone) prevented the inhibition of pulsatile secretion by progesterone during the luteal phase.

The seasonal changes in reproductive activity result from alteration in gonadotrophin secretion. The use of ovariectomized ewes treated with exogenous steroids provides a good model for studying these variations. Ovariectomized ewes with subcutaneous oestradiol implants show seasonal changes in $\mathrm{LH}$ secretion, a decrease in secretion occurring only at the time of anoestrus in intact animals (steroiddependent inhibition, Goodman et al., 1982; Martin et al., 1983). A concomitant seasonal change in the secretion of $\mathrm{LH}$ can also be observed in ovariectomized fernales that are not treated with oestradiol (steroid-independent inhibition), but the change is very small compared with that observed in treated animals. The changes in the secretion of LH result from variations in the frequency of LH pulses, which is controlled by similar modification in the frequency of GnRH emission within the hypothalamohypophysial portal vessels (Barrell et al., 1992). Thus, seasonal inhibition of reproductive activity in ewes during anoestrus is primarily controlled by the strengthening of the inhibition by oestradiol of the 
frequency of $\mathrm{GnRH}$ pulses. Alteration of reproductive activity therefore depends on the interaction between daylength and steroids.

\section{Transmitters and Hypothalamic Structures}

It has been demonstrated that transition from the breeding to the anoestrous season and vice versa results from inhibitory and stimulatory phenomena (Malpaux et al., 1989). However, knowledge of the involvement of the brain in seasonal regulation is mostly concerned with inhibitory effects. The first step in this field was probably provided by Goodman and Meyer (1984). Using anaesthetics to reduce neuronal activity, they observed release of LH pulses in anoestrous ewes subjected to pentobarbital anaesthesia, thus demonstrating that the inhibition is an active phenomenon. These results were rapidly followed by another study showing the catecholaminergic nature of the mechanism, as $\alpha$-adrenergic receptor blocking agents (dibenamine and phenoxybenzamine) and dopaminergic receptor blocking. agents (pimozide and fluphenazide) inhibit its effects (Meyer and Goodman, 1985).

Numerous studies of the structures involved in regulation have led to the suggestion that the anterior hypothalamus in ewes has a role. Domanski et al. (1972) reported that the breeding season was longer after electrolytic lesion of this area. Similarly, frontal deafferentation in this zone can block the effects of season on LH secretion (Przekop, 1978; Whisnant and Goodman, 1994). During spring, we performed electrical stimulation of the retrochiasmatic hypothalamus in ovariectomized ewes (Martin and Thiéry, 1987). This area contains the anterior part of the infundibular nucleus in the mid-sagittal position (equivalent to the arcuate nucleus of rats), and contiguous to it but more lateral is the lateral retrochiasmatic area. Electrical stimulation of the infundibular nucleus increases $\mathrm{LH}$, probably by direct activation of the GnRH fibres, while stimulation of the lateral retrochiasmatic area reduced the secretion of the hormone, suggesting the presence of neuronal elements inhibiting the GnRH neurones. This area contains the AI5 dopaminergic nucleus corresponding to the ventral part of the A15 nucleus of rats, and received a rich noradrenergic and a more scattered innervation by 5 -hydroxytryptamine, It is located just behind the optic chiasma, lateral to and distinct from the dopaminergic cell of the tuberoinfundibular system, named A12 (see Tillet, this supplement).

The catecholaminergic nature of the cells from an area showing inhibitory effects on GnRH secretion (Martin and Thiéry, 1987) together with the demonstration of the role of catecholamines in the inhibition of LH secretion (Meyer and Goodman, 1985) suggest the specific involvement of this structure in seasonal inhibition. To test this hypothesis, we injected 6-hydroxydopamine, a catecholaminergic specific neurotoxin, into the A15 nuclei and observed LH pulsatile secretion (Thiéry of al., 1989a): Destruction of only $20 \%$ of the dopaminergic cell bodies resulted in a threefold increase in pulsatile LH secretion in ovariectomized, oestradiol-treated ewes. These data suggest that the A15 nucleus is one of the key areas involved in the inhibition of LH by oestradiol during long days. These results are in agreement with later results from Havern et al. (1991) which show that the implantation of pimozide within the retrochiasmatic area and in the median eminence suppresses the inhibition of LH secretion in anoestrous ewes. Conversely, these authors have shown that the preoptic area may play a role through noradrenergic inputs, as implantation of phenoxybenzamine into this site also leads to LH release during this period.

This role of the A15 nucleus has been confirmed by Havern it al. (1994), who observed the release of $\mathrm{LH}$ pulses after radio frequency lesions of this nucleus, and proposed that the dopaminergic A14 nucleus located in the posteroventral part of the preoptic area also has an inhibitory role.

\section{Effect of Daylength and Oestradiol on Dopaminergic Activity}

The involvement of the A15 nucleus in the inhibition of LH by oestradiol under long days suggests that it could represent a good model for studying the interaction between steroids and daylength. In an attempt to examine this possible interaction, we observed the monoamines in several structures from the diencephalon of female sheep under various steroid treatments or light regimens. We measured the amines or their metabolites in 'punches' of tissues from regions containing GnRH axon terminals or cell bodies and intrinsic dopaminergic nuclei (Thiery, 1991). The most striking difference concerns the higher 


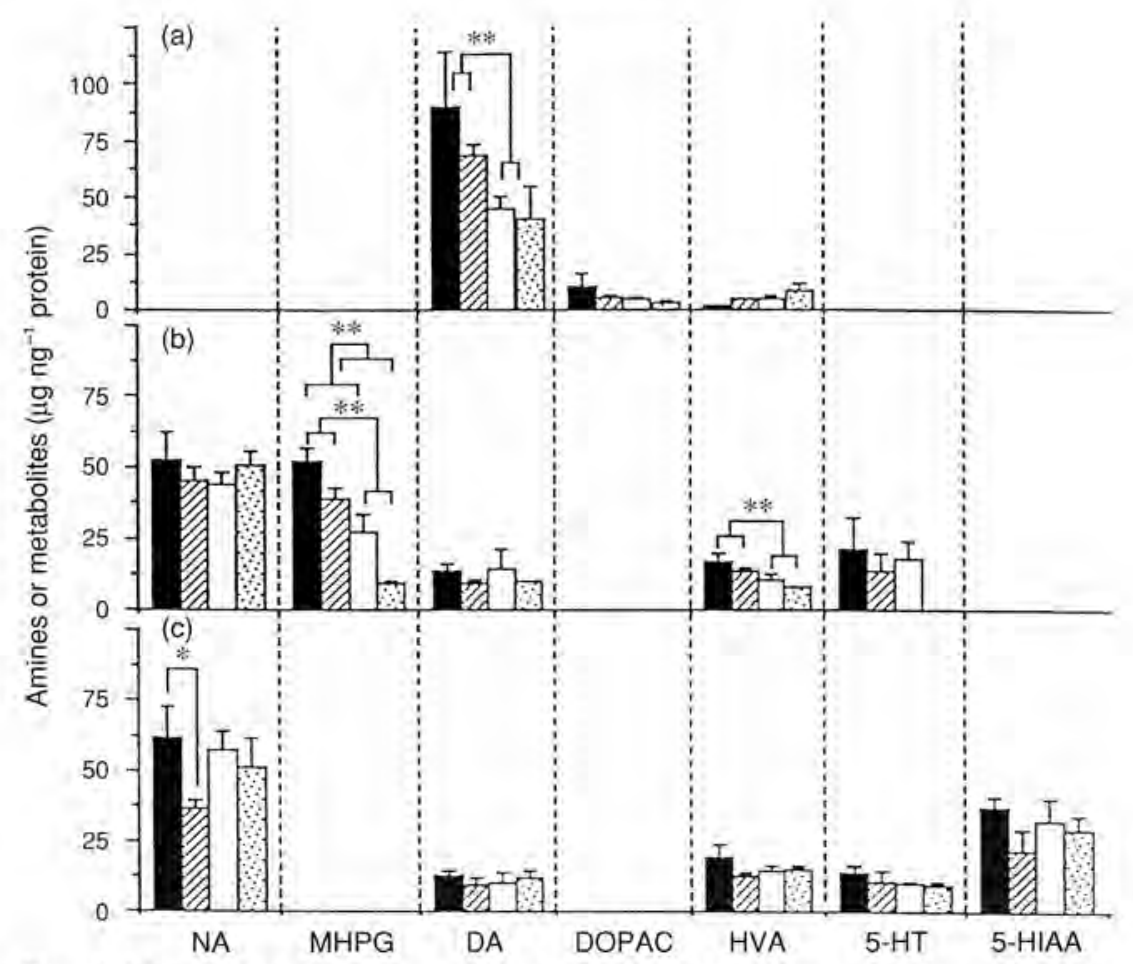

Fig. 2. Mean ( \pm SEM) tissue content of amines and amine metabolites in (a) the stalk-median eminence, (b) the infundibular nucleus and (c) the retrochiasmatic area containing the A15 nucleus from groups of four ewes subjected to various steroid treatments or light regimens. Long days, oestradiol treated (-); long days, without oestradiol ( $B$ ); short days, oestradiol treated $(\square)$; short days, without oestradiol $(\square)$. ${ }^{*} P<0.05,{ }^{* *} P<0.01$. NA: noradrenaline, MHPG 4-hydroxy-3-methoxyphenylglycol. DA: dopamine, DOPAC: 3,4-dihydroxyphenylacetic acid, HVA: homovanilic acid, 5-HT: 5-hydroxytryptamine, 5-HLAA: 5-hydroxy-indolacetic acid, Modified from Thiéry (1991).

content of dopamine found in the stalk-median eminence under long days than under short days. Similarly, more homovanilic acid and 3,4-dihydroxyphenylacetic acid, two metabolites of dopamine, and 4-hydroxy-3-methoxyphenylglycol, a metabolite of noradrenaline, were observed in the infundibular nucleus, without there being changes in the amines themselves (Fig. 2). Oestradiol alone increases 4-hydroxy-3-methoxyphenylglycol in the diencephalon during both seasons and in the A15 nucleus only during long days. Conversely, no significant changes in the content of monoamines from the septopreoptic structures were observed. Taken together, these results show an increase in catecholaminergic activity in the mediobasal hypothalamus during long days, reinforced by oestradiol in several structures, and suggest the involvement of the median eminence.

We have recently obtained additional data related to the role of dopamine from the median eminence in seasonal inhibition of $\mathrm{GnRH}$ secretion. Thiéry (1991) reported that the changes in monoaminergic activities were connected with steady states of $\mathrm{LH}$ secretion, during anoestrus versus the breeding season, long versus short days. When an artificial light regimen is used to bring female sheep into the breeding season, the abrupt shortening in daylength from long days ( $16 \mathrm{~h}$ light: $8 \mathrm{~h}$ dark) to short days ( $8 \mathrm{~h}$ light: $16 \mathrm{~h}$ dark) induces a decrease in prolactin secretion within 10 days. In contrast, the increase in pulsatile LH secretion occurs only after 40-50 days. The secretion of prolactin is inhibited by dopamine at the pituitary in sheep as in other mammals (see Curlewis, 1992 for review). Conversely, its secretion is stimulated centrally by the same molecule (Curlewis et al., I993). Thus, we question whether the seasonal changes in dopaminergic activity previously described were related to the regulation of prolactin or LH secretion. In an attempt to answer this question, Viguie et al. (1994) measured the 
activity of tyrosine hydroxylase in vitro in the median eminence of oestradiol-treated ovariectomized ewes killed under constant long days, or after 6, 24 or 74 short days. The results show only a decrease in tyrosine hydroxylase after 74 short days, when the LH inhibition was abolished, and not at 24 days, after the prolactin decrease. Thus, the changes in dopaminergic activity within the median eminence are associated with the modification of LH secretion rather than with the changes in prolactin secretion.

\section{Mechanisms of Action of Oestradiol on Dopaminergic Activity}

The mechanism of action of oestradiol on the activity of the A15 nucleus has been studied using the microdialysis method. Microdialysis enables the activity of the nucleus in the same animal to be compared under different treatments and allows the local manipulation of the catecholaminergic metabolism in awake, free-moving animals. In the first experiment, we performed two dialysis sessions on ovariectomized ewes, one after oestradiol treatment for 10 days and the other after 10 days without treatment (Gayrard et al, 1992). As expected, oestradiol caused a decline in pulsatile LH release, without affecting the secretion of prolactin. This steroid also led to an increase in the concentration of catecholamine metabolites, 4-hydroxy-3-methoxyphenylglycol, 3,4-dihydroxyphenylacetic acid and homovanilic acid, as well as in 5-hydroxy-indolacetic acid, a metabolite of 5-hydroxytryptamine (Fig. 3). Thus, oestradiol stimulates the dopaminergic activity of the A15 nucleus during long days. These results are in agreement with the results from Meyer and Goodman (1986), which show that injection of catecholamine agonists into ovariectomized animals inhibits pulsatile LH secretion in both the breeding and anoestrous seasons and thus suggest that the catecholaminergic system is stimulated during anoestrus rather than that there is a seasonal change in the number or sensitivity of the catecholaminergic receptors.

The absence of a significant increase in amines, with a concomitant increase in metabolites (Thierry, 1991; Gayrard et al., 1992), led to the suggestion that there is a stimulation of the turnover of the monoamines. Such an alteration could result from changes either in the rate of synthesis or degradation, involving respectively, tyrosine hydroxylase, the rate-limiting enzyme, or the monoamine oxidase activities (Fig. 1). To determine whether oestradiol could alter the turnover of catecholamines from the A15 nucleus, we used a method involving the local perfusion of an inhibitor of L-aromatic amino acid decarboxylase by the dialysis probe. Blockade of this enzyme leads to accumulation of L-3-4dihydroxyphenylalanine, the concentration of which is monitored by the probe (Gayrard et al., 1994). We observed that the accumulation of L-3-4-dihydroxyphenylalanine was significantly stimulated by oestradiol in the A15 nucleus of ovariectomized ewes (Fig. 4). This result is in agreement with the hypothesis that oestradiol stimulates tyrosine hydroxylase activity. We also measured extracellular amine metabolites and tyrosine hydroxylase activity in vivo in the A15 nucleus in which $45 \%$ of the activity of the noradrenergic terminals had been abolished by a specific neurotoxin lesion, leaving the dopaminergic cells intact. The lesion results in a decrease of 4-hydroxy-3-methoxyphenylglycol with a compensatory increase in 5-hydroxy-indolacetic acid (Fig. 5), while the LH inhibition was maintained. Conversely, the accumulation of L-3-4-dihydroxyphenylalanine following blockade of L-aromatic amino acid decarboxylase was similar in lesioned and control animals. Thus, the oestradiol stimulated increase in tyrosine hydroxylase activity in the A15 nucleus appears to be due to a specific increase in the dopaminergic cell bodies, and not to the noradrenergic terminals present in the nucleus. Furthermore, these noradrenergic terminals do not seem to be required for the expression of LH inhibition.

\section{Site of Action of Oestradiol on Dopaminergic Activity}

The site of action of oestradiol on the dopaminergic system remains unknown. Localization of oestradiol receptors in the brain of sheep has been performed using histochemistry in several studies, and has shown colocalization of these receptors on some dopaminergic cell bodies from the A12 nucleus, but oestradiol receptors were not found in the A15 or A14 nuclei (Lehman and Karsch, 1993; Tillet, this supplement). There are many reports that oestradiol stimulates dopaminergic activity in rats (see Ben-Jonathan, 1985, for review). However, in most of the experiments, the stimulation results from a 
primary stimulation of prolactin secretion which in turn stimulates dopaminergic activity. The little evidence of the direct effect of oestradiol in dopaminergic neurones from the hypothalamus almost consistently shows inhibition (Pasqualini et al., 1991). Thus, a direct stimulatory effect in sheep is unlikely

(a)
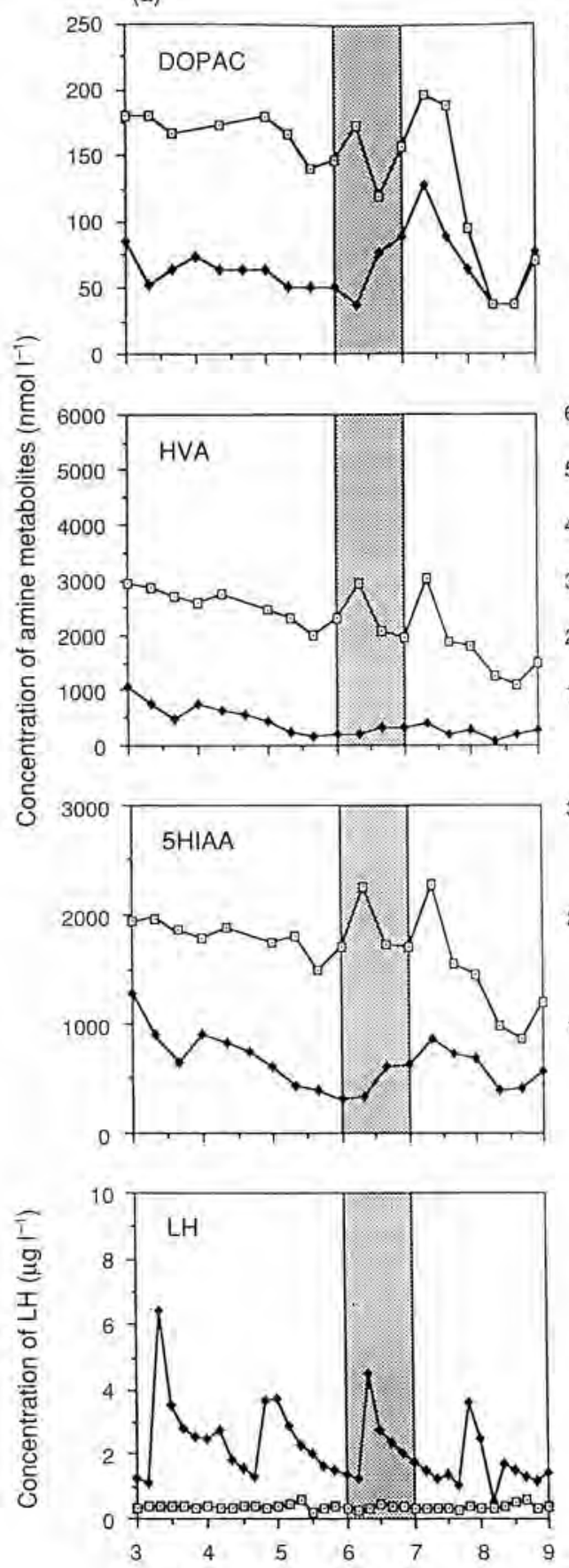

(b)
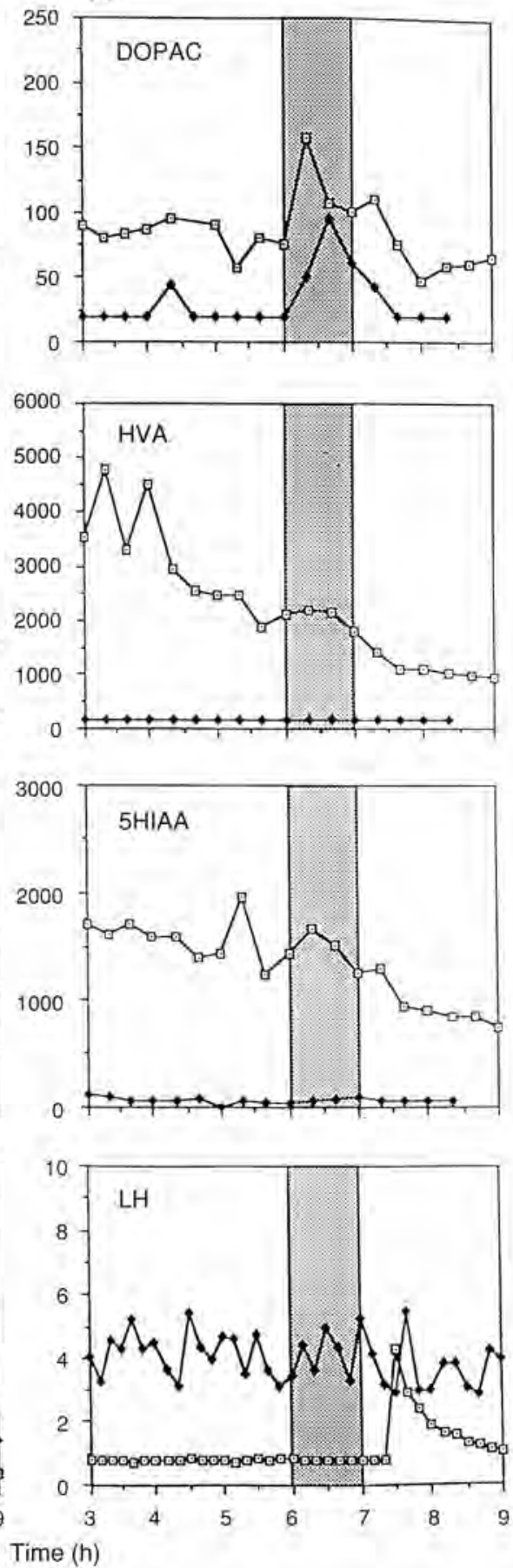
and it is possible that intermediate neuronal systems are involved. Consequently, we postulate that the effect is conveyed through innervations of the nucleus.

Noradrenaline and 5-hydroxytryptamine terminals could represent good candidates for this role. As there are oestradiol receptors in some of the noradrenergic cell bodies from the mesencephalon in rats (Heritage et al., 1977), and as 4-hydroxy-3-methoxyphenylglycol increases in oestradiol-treated ewes under long days (Thiéry, 1991), we may question whether the noradrenergic terminals from the A15 are involved in the steroid-dependent inhibition of LH secretion. After pharmacological investigations, Goodman (1989) suggested that noradrenergic inputs precede dopaminergic inputs in a cascade of events leading to the inhibition of $\mathrm{LH}$ secretion during anoestrus. However, as stated earlier, it is unlikely that this cascade takes place in the A15 nucleus, as destruction of $45 \%$ of its innervation does not prevent the stimulation of tyrosine hydroxylase activity or the inhibition of LH secretion (Gayrard et al., 1994). Similarly, the increase in 5-hydroxy-indolacetic acid under oestradiol treatment (Gayrard et al, $1992,1994)$ supports the contention that 5 -hydroxytryptamine is involved. The destruction of noradrenergic terminals (Gayrard et al., 1994) was accompanied by a compensatory increase in 5-hydroxy-indolacetic acid content of the nucleus in the lesioned animals, suggesting the interaction of the two innervations. However, their role as interneurones between the oestradiol receptors and the A15 nucleus remain to be established. Havern et al. (1994) suggested that there is an atomical relationship between A14 and A15. As the preoptic area contains oestradiol receptors (see Herbison, this supplement), it is possible that there is a pathway between these preoptic receptors, the A14 nucleus and then the A15 nucleus.

\section{Site of Action of Dopamine on GnRH Neurones}

In a first attempt to identify the possible links between the A15 nucleus and the GnRH neurones, we injected neurotoxin into the nucleus and looked for changes in the amine content of the septopreoptic region, where the GnRH cell bodies are, and the median eminence, where the terminals of the GnRH cells are (Thiéry et al., 1989b). We observed a large reduction in dopamine, 3,4-dihydroxyphenylacetic acid and homovanilic acid contents in the stalk eminence, as well as a decrease in dopamine, 3,4-dihydroxyphenylacetic acid and noradrenaline contents in the infundibular nucleus, suggesting a functional relationship between the A15 nucleus, the mediobasal hypothalamus and the median eminence. Deaver et al. (1987) showed a modulation in the release of LH after peripherally administered domperidone. Since domperidone cannot pass the blood-brain barrier, this treatment could have affected only the median eminence. The involvement of the median eminence strongly suggests an inhibitory action of dopamine through presynaptic inhibition of the GnRH axon terminals. Results from some anatomical studies support this hypothesis, namely the presence of catecholaminergic terminals close to those of GnRH within the median eminence (Kuljis and Advis, I989). However, there is no definite anatomical proof. The effectiveness of the D2 antagonist pimozide in stimulating LH secretion as well as the use of the D2 agonist to inhibit the LH pulses (Curlewis et al., 1991) suggest the involvement of a D2 class of dopaminergic receptors.

\section{Other Effects of Dopamine in Inhibition of Reproductive Activity}

In ruminants, dopamine appears to be the major monoaminergic transmitter involved in the inhibition of gonadotrophin secretion. Dopamine may also participate in the prepubertal inhibition of

Fig. 3. Temporal variations in the concentration of amine metabolites: DOPAC: 3,4-dihydroxyphenylacetic acid: HVA: homovanilic acid; 5HIAA; 5-hydroxy-indolacetic acid in the dialysate of the A15 nucleus and the concomitant concentration of LH in plasma for two representative ewes either treated $(\epsilon)$ or not-treated with oestradiol $(\bullet)$. Dialysate was collected every $20 \mathrm{~min}$ for $9 \mathrm{~h}$. The first $3 \mathrm{~h}$, the time taken for the concentrations to return to basal values after implantation of the probe, are not shown here. Desipramine, a re-uptake blocker of noradrenergic terminals was added to the perfusion medium during the seventh hour and resulted in stimulation of the monoaminergic tone of the structure (shaded area). Reproduced from Gayrard of al., 1992, with permission of the Journal of Endocrinology Ltd. 


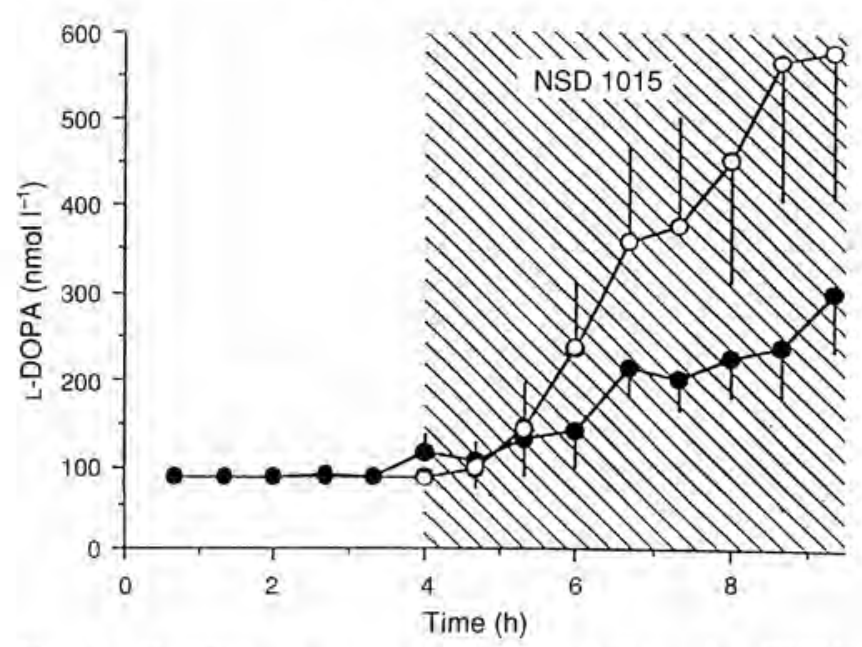

Fig. 4. Variation in extracellular concentration of L-DOPA (mean \pm SEM) in the retrochiasmatic area in six ewes either treated $(O)$ or not treated with oestradiol $(\bullet)$. The shaded area represents the time at which NSD I015, a specific inhibitor of L-aromatic amino acid decarboxylase (AADC) which allowed accumulation of $L-D O P A$, was added to the perfusion medium. Modified with permission from Gayrard ef al. (1994).

gonadotrophin secretion, since peripheral pimozide injections can stimulate LH pulses in prepubertal ewe lambs (Brango et al., 1990), but the brain structures involved are still unknown. In young male sheep, changes in dopamine content of the median eminence are also concomitant with a modification of gonadotrophin secretion around puberty (Jenkins et al., 1986), a result quite similar to the modification observed in bull calves (Deaver and Peters, 1988). In rodents, there are many reports of both stimulatory and inhibitory effects of dopamine, corresponding to the involvement of different catecholaminergic structures and different physiological situations. In white-footed mice and Syrian hamsters, two photoperiodic rodents, the presence of dopamine from the median eminence is also correlated with the inhibition of gonadotrophin release, which takes place under short days in these species (Steger et al, 1985; Glass et al. 1988). In rats. non-photoperiodic rodents, the intrinsic dopaminergic nuclei from the hypothalamus could participate in the stimulation of the preovulatory release of $\mathrm{LH}$ (positive feedback from oestradiol) through D1 receptors, while these nuclei could be involved in the inhibition of $\mathrm{LH}$ (negative feedback from the steroid) through D2 receptors (Tadakoro et al, 1986). Dopamine has been shown to inhibit LH secretion in prepubertal rats (Lacau-Mengido et al., 1993).

Thus, dopamine from the intrinsic nuclei from the hypothalamus in mammals often appears to be linked with the inhibition of LH by oestradiol under various circumstances, such as photoperiodic or prepubertal inhibition. Most of its effects seems to be to alter LH secretion through GnRH inhibition and involve D2 receptors. In teleost fish, dopamine also inhibits gonadotrophin secretion. In the goldfish, Carassius auratus, dopamine acts directly within the pituitary gland on the gonadotrophic cells, where it inhibits the effect of GnRH and diminishes GnRH release, probably through presynaptic inhibition involving D2 receptors (Peter et al, 1991). In the European silver eel, Anguilla anguilla, dopamine also participates in the inhibition of the secretion of gonadotrophins during the prepubertal period (Dufour et al., 1991). In the hibernating frog, Rana temporana, it has recently been shown that dopamine could play a major role in the seasonal control of reproduction by inhibitory effects during hibernation (Sotowska-Brochocka ef al., 1994). Finally, inhibitory control of GnRH secretion by dopamine has also been shown in birds (Sharp et al, 1989). At least in the two last mentioned groups of animals a central effect is suggested. 

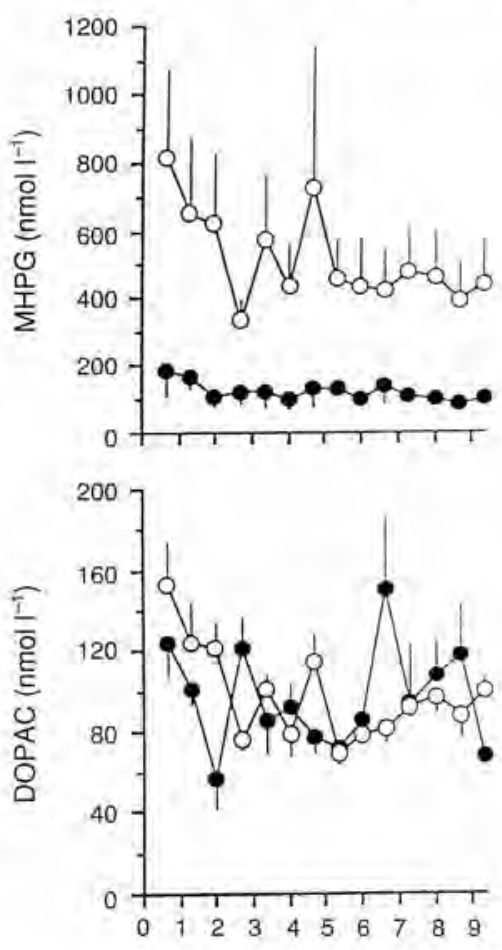
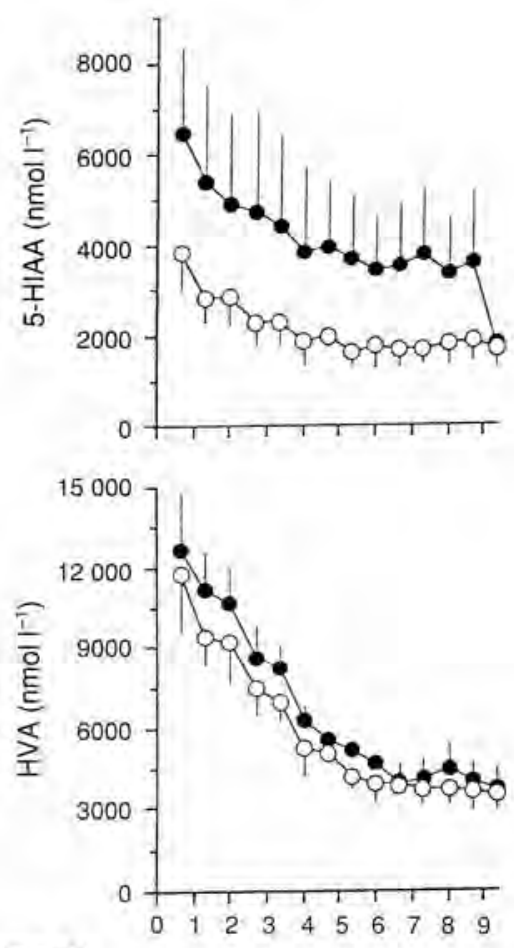

Time (h)

Fig. 5. Extracellular concentration of amine metabolites (mean \pm SEM). DOPAC: 3,4dihydroxyphenylacetic acid; MHPG: 4-hydroxy-3-methoxyphenylglycol; HVA: homovanilic acid: 5-HIAA: 5-hydroxy-indolacetic acid, in the retrochiasmatic area of four ovariectomized oestradiol-treated ewes from the control group (C) and from the group of four animals in which the noradrenergic terminals were partially $(45 \%)$ destroyed $(\bullet)$. This destruction was performed by intra-cerebroventricular injection of 6-hydroxydopamine following protection of the dopaminergic cell bodies by a pretreatment with nomifensine, a specific inhibitor of re-uptake of dopaminergic elements. Note the decrease in MHPG, a metabolite of noradrenaline, and the concomitant increase in 5-HIAA, a metabolite of 5-hydroxytryptamine. Modified with permission from Gayrard et al. (1994).

\section{Involvement of 5-Hydroxytryptamine in Seasonal Regulation of LH Secretion}

Among monoamines, 5-hydroxytryptamine has often been shown to play either a stimulatory or inhibitory role in gonadotrophin secretion in female rats (Morello and Taleisnik, 1985). In female sheep, the role seems to be essentially inhibitory (Domanski et al, 1975). The ability of cyproheptadine, a 5-HT antagonist, to increase the frequency of LH pulsatile release in ovariectomized ewes that were not treated with oestradiol during the anoestrous period suggests the participation of 5-HT in the steroid-independent inhibition of LH secretion during long days (Meyer and Goodman, 1986). However, Le Corre and Chemineau (1993a, b), also showed that 5-hydroxytryptamine antagonists release LH in ovariectomized ewes treated with oestradiol. The role of 5-hydroxytryptamine, which seems to involve the $5-\mathrm{HT}_{2}$ receptors, appears stronger during the inhibition corresponding to the refractoriness to short days than during the inhibition due to long days. Such variations in the effect of 5-hydroxytryptamine could involve changes in the $5-\mathrm{HT}_{2}$ receptors as changes in their density within the ventrolateral part of the mediobasal hypothalamus accompany photoperiodic alteration in LH secretion (Le Corre et al, 1994). We can question whether the oestradiol-dependent changes in 5-hydroxytryptamine activity observed by Gayrard et al. $(1992,1994)$ are connected to the role of 5-hydroxytryptamine suggested by the results from Le Corre and Chemineau (I993a, b). 


\section{Conclusion}

The role of the A15 dopaminergic nucleus in the inhibition of GnRH pulsatile secretion by oestradiol under long days in female sheep now appears well established. Dopaminergic activity is stimulated by long daylength together with oestradiol, through activation of tyrosine hydroxylase, the rate limiting enzyme of the biosynthesis pathway. Dopamine thereafter increases in the median eminence and acts through D2 receptors. This cascade of events results in a decrease of GnRH secretion. This role of dopamine resembles that of other dopaminergic regulations described in the control of reproduction in various groups of vertebrates and could suggest an old phylogenetic way for the control of reproductive activity. Several important questions concerning the A15 nucleus in ewes remain. Do oestradiol and light (probably via melatonin), the two inputs to the system, act directly or through interneurones? Does the output of the system, the dopaminergic tone, act directly on the $\mathrm{GnRH}$ neurones within the median eminence? If the answer to the second question is positive, the seasonal regulation of $\mathrm{GnRH}$ output is acting only through presynaptic inhibition of a neurosecretory mechanism. Conversely, if there are intermediate systems, they could also affect any other part of the GnRH system, including the activity of the cell bodies or the synthesis of the neurohormone. The putative interneurones could be monoaminergic but could also involve amino acid or neuropeptide neurotransmitters. In other words, we can question whether the A15 nucleus is one of the final inhibitory pathways participating in the control of $\mathrm{GnRH}$ secretion or whether it is an obligatory crossroad in the system integrating daylength and the oestradiol effect. Numerous additional experiments will be required to answer these questions.

The authors would like to thank the Intervet International Company for financial help and D. Nowak who prepared the English translation of the manuscript.

\section{References}

Barrell GK, Moenter SM, Caraty A and Karsch FJ (1992) Seasonal changes of gonadotropin-releasing hormone secretion in the ewe Biology of Reproduction 46 $1130-1135$

Ben-Jonathan N (1985) Dopamine: a prolactin inhibiting hormone Endocrine Review 6 564-589

Brango CW, Whisnant CS and Goodman RL (1990) A role of catecholaminergic neurons in the suppression of pulsatile luteinizing hormone secretion in the prepubertal ewe lamb Neurvendocrinology $\mathbf{5 2} \quad 448-484$

Curlewis JD (1992) Seasonal prolactin secretion and its role in seasonal reproduction - a review Reproduction Fertilily and Development $4 \mathrm{I}-23$

Curlewis JD, Naylor AM and McNeilly AS (1991) Evaluation of a possible role for the dopamine D1 and D2 receptors in the steroid dependent suppression of luteinizing hormone secretion in the seasonally anoestrous ewe Joumal of Neuroendocrinology 3 387-391

Curlewis ID, Clarke IJ and McNeilly AS (1993) Dopamine DI receptor analogues act certrally to stimulate prolactin secretion in ewes Jourmal of Endocrinology 137 457-464

Deaver DR and Peters JL (1988) Age-related changes in secretion of luteinizing hormone and metabolism of hypothalamic amines in bull calves prior to puberty Biology of Reproduction $39622-629$

Deaver DR, Keisler DH and Dailey RA (1987) Effects of domperidone and thyrotropin-releasing hormone on secretion of luteinizing hormone and prolactin during the luteal phase and following induction of luteal regression in sheep Domestic Animal Endocrimolog! $495-102$
Domanski E, Przekop F and Skubiszewski B (1972) The role of the anterior region of the medial basal hypothalamus in the control of ovulation and sexual behaviour in sheep Acta Neurobiologica Experimentia $32 \quad 753-762$

Domanski E, Przekop F, Skubiszewski B and Wolinska E (1975) The effect and sitte of action of indoleamines on the hypothalamic centers involved in the control of $\mathrm{LH}$ release and ovulation in sheep Neuroendocinology 17 265-273

Dufour S, Bassompierre M, Montero M, Le Belle N, Baloche S and Fontaine YA (1991) Stimulation of pituitary gonadotropic function in female silver eel treated by a gonadoliberin agonist and dopamine antagonists. In Proceedings of the Fourth International Symposiom on the Reproductive Physiology of Fish pp 54-56 Eds AP Scott, JP Sumper, DE Kime and MS Rolfe. Published by Fishsymp. Sheffield

Gayrard V, Malpaux B and Thiéry J-C (1992) Oestradiol increases the extracellular levels of amine metabolites in the ewe hypothalamus during anoestrus - a mierodialysis study Journal of Endoctiniology 135 421-431

Gayrard V, Malpaux B, Tillet Y and Thiéry J-C (1994) Estradiol increases tyrosine hydroxylase actiyity of the A15 nucleus dopaminergic neurons during long days in the ewe Biology of Reproduction 50 1168-1177

Glass JD, Ferrera S and Deaver DR (1988) Photoperiodic adjustment in hypothalamic amines gonadotrophinreleasing hormone and $\beta$-endorphin in white-footed mouse Endocrinology $1231119-1127$

Goodman RL (1989) Functional organization of the catecholaminergic neural systems inhibiting luteinizing hormone secretion in anestrous ewes Neuroendocrinology $50406-412$ 
Goodman RL and Meyer SL. (1984) Effect of pentobarbital anaesthesia on tonic luteinizing hormone secretion in the ewe. Evidence for active inhibition of luteinizing hormone in anoestrus Biology of Reproduction 30 374-381

Goodman RL, Bittman EL, Foster DL and Karsch FJ (1982) Alterations in the control of luteinizing hormone pulse frequency underlie the seasonal variation in estradiol negative feedback in the ewe Biology of Reproduction 27 $580-589$

Havern RL, Whisnant CS and Goodman RL (1991) Hypothalamic sites of catecholamine inhibition of luteinizing hormone in the anestrous ewe Biology of Reproduction 44 476-482

Havern RL, Whisnant CS and Goodman RL (1994) Dopaminergic structures in the ovine hypothalamus mediating estradiol negative feedback in anestrous ewes Endocrinology 134 $1905-1914$

Heritage AS, Grant LD and Stumpf W (1977) ${ }^{3} \mathrm{H}$-estradiol in catecholamine neurons of rat brain stem: combined local. ization by autoradiographic formaldehyde-induced fluorescence Joumal of Comparative Neurology 176 607-630

Jenkins N, Knight PG, Howles CM, Morris BA and Waites GMH (1986) Effect of passive immunisation against oestradiol$17 \beta$ on some endocrines values of the male lamb Journal of Reproduction and Ferfility 78 28I-286

Karsch FJ, Bittman EL, Robinson JE, Yellon SM, Wayne NL, Olster DH and Kaynard AH (1986) Melatonin and refractoriness: loss of response to the melatonin signal leads to seasonal reproductive transition in the ewe Biology of Reproduction $34 \quad 265-274$

Kuljis RO and Advis IP (1989) Immunocytochemical and physiological evidence of a synapse between dopamine and luteinizing hormone releasing hormone-containing neurons in the ewe median eminence Endocrinology 124 1579-1581

Lacau-Mengido IM, Becu-Villalobos D, Thyssen SM, Rey EB, Luxlantos VAR and Libertun C (1993) Antidopaminergicinduced hypothalamic LHRH release and pituitary gonadotrophin secretion in 12-day-old female and male rats jountal of Neuroendocrinology 5 705-709

Le Corre S and Chemineau P (1993a) Serotonergic 5HT(2)receptors mediate the intubitory action of 5 hydroxytryptamine on luteinizing hormone secretion in ovariectomized estradiol-treated ewes that are refractory to short days Biology of Reproduction 49 140-147

Le Corre S and Chemineau P (1993b) Control of photoperiodic inhibition of luteinizing hormone secretion by dopaminergic and serotonergic systems in ovariectomized llede-France ewes supplemented with oestradiol Joumal of Reproduction and Fertility $97367-373$

Le Corre S, Segu L, Caldani M and Chemineau P (1994) Differences in katanserin binding in the ventro-medial hypothalamus of ewes responsive or refractory to short days Neuroendocrinology 60 589-600

Lehman MN and Karsch FJ (1993) Do gonadotropin-releasing hormone, tyrosine hydroxylase-immunoreactive and betaendorphin-immunoreactive neurons contain estrogen receptors? A double-label immunocytochenical study in the Suffolk ewe Endocrinology 133 887-895

Malpaux B, Robinson JE, Wayne NL and Karsch FJ (1989) Regulation of the onset of the breeding season of the ewe: importance of long days and of an endogenous reproductive thythm Journal of Endocrinology 122 269-278

Malpaux B, Daveau A, Maurice F, Gayrard V and Thiéry J-C (1993) Short day effects of melatonin on luteinizing hormone secretion in the ewe evidence for a central site of action in the mediobasal hypothalamus Biology of Reproducfion 48 752-760

Malpaux B, Daveau A, Maurice F, Locatelli A and Thiéry J-C (1994) Evidence that melatonin binding sites in the pars tuberalis do not mediate the photoperiodic actions of melatonin on $\mathrm{LH}$ and prolactin secretion in the ewe Joumal of Reproduction and Fertility 101 625-632

Martin GB and Thiéry J-C (1987) Hypothalamic multiunit activity and LH secretion in conscious sheep Experimental Brain Research $67469-478$

Martin GB, Scaramuzzi RJ and Henstridge JD (1983) Effects of oestradiol, progesterone and androstenedione on the pulsatile secretion of luteinizing hormone in ovariectomized ewes during spring and autumn Journal of Endocrinology 96 $181-193$

Meyer SL and Goodman RL (1985) Neurotransmitters involved in mediating the steroid-dependent suppression of pulsatile luteinizing hormone secretion in anoestrous ewes: effects of receptors antagonists Endocrinology 116 2054-2001

Meyer SL and Goodman RL (1986) Separate neural systems mediate the steroid-dependent and steroid-independent suppression of tonic luteinizing hormone secretion in the anoestrus ewe Biology of Reproduction $35562-571$

Morello $\mathrm{H}$ and Taleisnik S (1985) Changes of the release of luteinizing hormone $(\mathrm{LH})$ on the day of proestrus after lesion or stimulation of the raphe nuclei in rats Brain Research $360311-317$

Pasqualini C, Leviel V, Guibert B, Fauconbiguet $\mathrm{N}$ and Kerdelhue B (1991) Inhibitory actions of acute estradiol treatment on the activity and quantity of tyrosine hydroxylase in the median eminence of ovariectomized rats Joumal of Nenroendocrinology 3 575-580

Peter RE, Trudeau VL, Sloley BD, Peng C and Nahorniak CS (1991) Actions of catecholamines, peptides and sex steroids in regulation of gonadotropin-II in the goldfish In Proceedings of the Fourth International Symposian on the Reproductive Physiology of Fisht pp $30-34$ Eds AP Scott, JP Sumper, DE Kime and MS Rolfe: Published by Fishsymp, Sheffield

Przekop F (1978) Effect of anterior deafferentation of the hypothalamus on the release of luteinizing (LH) and reproduction in sheep Acta Physiologia Polonikat 29 393-407

Sharp PJ, Talbot RT and Macnamee MC (1989) Evidence for the involvement of dopamine and 5-hydroxytryptamine in the regulation of the preovulatory release of luteinizing hormone in the domestic hen General and Comparative Endocrinology 76 205-213

Sotowska-Brochocka J, Martynska L and Licht P (1994) Dopaminergic inhibition of gonadotropic release in hibemating frogs, Rana temporatia General and Comparative Endocrinol. ogy 93 192-196

Steger RW, Matt KS, Klemke HG and Bartke A (1985) Interactions of photoperiod and ectopic graphs on hypothalamic and pituitary function in male hamsters Neuroendocrinology 41 89-96

Tadakoro Y, Akema T and Kimura F (1986) Dopaminergic involvement in the estrogen-induced suppression of frequency of pulsatile luteinizing homone secretion in the ovariectomized rat Brain Research 380 69-75

Thiéry J-C (1991) Monoamine content of the stalk-median eminence and hypothalamus in adult female sheep as affected by daylength Joumal of Neuroendocrinologty 3 $407-411$ 
Thiéry J-C and Martin GB (1991) Neurophysiological control of the secretion of gonadotrophin-releasing hormone and luteinizing homone in the sheep - a review Reproduction Ferfility and Development 3 137-173

Thiéry J-C, Martin GB, Tillet $\gamma$, Caldani M, Quentin M, Jamain C and Ravault JP (1989a) Role of hypothalamic catecholamines in the regulation of LH and prolactin secretion in the ewe during seasonal anoestrus Neuroendocrinology 49 $80-87$

Thiéry J-C. Godou F, Tillet $\mathrm{Y}$, Caldini M, Batailler M and Kendelhue B (1989b) Determination of monoamines and their metabolites in the hypothalamus of the fernale sheep Annales d'Endocrinologie $5050 \mathrm{~N}$

Viguié C, Thibault J, Thiéry J-C, Tillet $\mathrm{Y}$ and Malpaux B (1994)

Reduction of tyrosine hydroxylase activity in the median eminence of the ewe by short days in relation to changes in luteinizing hormone and prolactin secretion. Biology of Reproduction 50 (Supplement 1), Abstract 214

Whisnant CS and Goodman RL (1994) Effect of anterior hypothalamic deafferentiation on the negative feedback of gonadal steroids on luteinizing hormone pulse frequency in the ewe Domestic Animal Endocrinology 11 151-159 